\title{
Linkage analysis in multiple sclerosis of chromosomal regions syntenic to experimental autoimmune disease loci
}

\author{
Chun $\mathrm{Xu}^{1}$, Yamei Dai ${ }^{1}$, Johnny C Lorentzen ${ }^{2}$, Ingrid Dahlman ${ }^{3}$, Tomas Olsson ${ }^{3}$ and \\ Jan Hillert*,1 \\ ${ }^{1}$ Division of Neurology, Karolinska Institute at Huddinge University Hospital, S-14186 Huddinge, Sweden; \\ ${ }^{2}$ Rheumatology Unit, Center for Molecular Medicine (CMM), Karolinska Hospital, S-171 76 Stockholm, Sweden; \\ ${ }^{3}$ Neuroimmunology Unit, Center for Molecular Medicine (CMM), Karolinska Hospital, S-171 76 Stockholm, Sweden
}

Multiple sclerosis is a demyelinating disorder of the central nervous system with a putative autoimmune aetiology in which several genes are thought to be involved. Four published genomic screens have confirmed that a gene influencing MS resides within or close to the HLA class II region in 6p21. Still, this locus is likely to confer only a part of the genetic susceptibility in MS. Further, all four studies identified a number of other regions with possible linkage. We have investigated eight chromosomal intervals syntenic to loci of importance for experimental autoimmune model diseases in the rat in $\mathbf{7 4}$ Swedish MS families. Possible linkage (a non-parametric linkage NPL score of 1.16 by GENEHUNTER computer package) was observed with markers in 12p13.3, a region syntenic to the rat Oia2 locus which is importance for oil induced arthritis (OIA). Four markers in the T cell receptor $\beta$ chain gene region in 7q35 showed possible linkage (highest NPL score of 1.16). This locus is syntenic to the rat Cia3 locus (collagen induced arthritis). These two loci at least partially overlap with chromosomal regions showing indicative evidence for linkage in the previous MS genomic screens. Indeed, both Oia2 and $\mathrm{Cia} 3$ were recently found to be linked also with experimental autoimmune encephalomyelitis, a commonly used model for MS. Markers in 2p12, 3p25, 10q11.23, 17q21-25, 19q13.1, and 22q12-13 failed to provide evidence for linkage. We conclude that evidence is amounting that 12p13-12 and 7q34-36 may harbour genes with an importance for MS. The synteny with experimental loci may eventually facilitate their identification. European Journal of Human Genetics (2001) 9, 458-463.

Keywords: experimental arthritis; experimental autoimmune encephalomyelitis; genetic susceptibility; genetic linkage; multiple sclerosis; synteny

\section{Introduction}

Multiple sclerosis (MS) is a chronic inflammatory disease of the central nervous system characterised by damage to axonal myelin sheaths and axons, commonly resulting in progressive neurological disability beginning in early adulthood. MS is most prevalent in populations of northern

*Correspondence: J Hillert, Department of Neurology, Karolinska Institute at Huddinge University Hospital, S-14186 Huddinge, Sweden. Tel: +46 85858 2056; Fax: +46 85858 7080;

E-mail: jan.hillert@neurotec.ki.se

Received 1 December 2000; revised 8 March 2001; accepted 14 March 2001
European descent. ${ }^{1}$ Twin and adoption studies provide strong evidence for a genetic contribution to the susceptibility of MS. ${ }^{2}$

It is well established that one gene influencing MS is located within or close to the HLA class II gene region. ${ }^{3}$ This is consistent with the notion that MS is a T cell-mediated autoimmune disease, and, therefore, other genes controlling the immune response have been studied as potential susceptibility factors in MS. However, results have been inconsistent (for a review, see $^{4}$ ).

Four groups ${ }^{5-8}$ reported full genomic screens using large numbers of microsatellite markers in MS families. All four studies confirmed the importance of the HLA gene complex 
in 6 p21, and, in addition, reported weak linkage to other loci. Interestingly, linkage to one of these loci was also suggested by Kuokkanen, ${ }^{9}$ who used a candidate approach to $5 \mathrm{p}$, guided by linkage to the syntenic locus in mouse to experimental autoimmune encephalomyelitis (EAE). ${ }^{10}$

Recently, a number of genomic regions regulating disease have been mapped in various experimental organ-specific inflammatory disease models. In the rat, these include insulin dependent diabetes mellitus (IDDM), autoimmune thyroid disease (ATD), experimental autoimmune encephalomyelitis (EAE), collagen-induced arthritis (CIA) and oilinduced arthritis (OIA) ${ }^{11-17}$ In addition, susceptibility loci for specific autoimmune diseases appear to overlap with each other ${ }^{18}$ suggesting that common genes or mechanisms are influencing different organ-specific inflammatory diseases.

Here, we have investigated the potential importance in MS of loci likely to be syntenic to chromosomal intervals that influence susceptibility to autoimmune disease in DA rats. Five quantitative trait loci (QTL) were originally identified by whole genome scans in CIA (Cia2-5) and OIA (Oia2). ${ }^{16,17} \mathrm{We}$ postulated that they might be of importance in autoimmunity or inflammation since DA rats are highly susceptible to many models of autoimmune diseases. Indeed, three of these loci were recently demonstrated to influence phenotypes of EAE induced by myelin oligodendrocyte glycoprotein (MOG) in DA rats (ie Cia3, Cia5 and Oia2). ${ }^{13,19}$

Twenty-seven microsatellite markers were investigated for linkage in 74 Swedish MS families. Markers in two chromosomal regions, 7q34-36 and 12p13-12, syntenic to Cia3 and Oia2, respectively, provided evidence for possible linkage. In addition, both were among those of possible importance according to previous genomic screens in MS. ${ }^{5-8}$ Our observations indicate that genetic polymorphisms in these loci may influence immune regulation promoting autoimmune diseases regardless of target organ and species.

\section{Materials and methods}

Families and controls

All individuals were drawn from the relatively homogenous Swedish population. MS was diagnosed on the basis of clinical and paraclinical investigations. ${ }^{20}$ Two hundred and eighty-six individuals were studied, including 132 patients. Types of families and numbers of patients are indicated in Table 1. Besides families, 148 ethnically matched healthy controls were used for determining allele frequencies. The study was approved by the local ethics committee.

\section{Genotyping}

Genomic DNA was extracted from peripheral blood leucocytes using a modified salting-out protocol. ${ }^{21}$ Polymerase chain reaction (PCR) was employed in $7 \mu \mathrm{l}$ reaction volumes. Four hundred and thirty-three individuals were genotyped for 27 polymorphic markers corresponding to dinucleotide $(n=17)$, trinucleotide $(n=1)$, tetranucleotide $(n=8)$ and penta- nucleotide $(n=1)$ repeats (Table 2$)$. The Primers were synthesised by Scandinavian Gene Synthesis AB and forward primers for each primer pair were labelled with $5^{\prime}$ - FAM, HEX, or TET phosphoramidites (Köping, Sweden). Optimal PCR conditions consisted of $95^{\circ} \mathrm{C}$ for $1 \mathrm{~min}, 55^{\circ} \mathrm{C}$ for $40 \mathrm{~s}$ and $72^{\circ} \mathrm{C}$ for 1 min with 30 cycles by a PCR cycle 9600 (Perkin Elmer), but may vary slightly among the markers. Genotyping was carried out using fluorescently labelled oligonucleotides in the semiautomatic GENESCAN/GENOTYPER system on an Applied BioSystems 377 DNA sequencing equipment, PCR products were diluted and $1.5 \mu \mathrm{l}$ was combined with $2.5 \mu \mathrm{l}$ internal lane size standard mixture (Genescan-350 or -500 TAMRA, Applied BioSystems). The accuracy and reproducibility of automated sizing of fragments was further confirmed by randomly chosen repeated analyses of identical samples and two readers independently reading data. Genotypes that were found to be inconsistent or which were discrepant between the two readers were either repeated or discarded.

\section{Synteny and markers}

The identification of syntenic segments between rat and human chromosomal loci was achieved by comparing available mapping data for identified genes in human, mouse and rat genome database and homology map on the web sites (http://www.gdb.org, http://ratmap.gen.gu.se, http:// www.informatics.jax.org, http://www.ncbi.nlm.nih.gov/ Homology). The primer sequences of used markers were taken from human genome database (http://www.gdb.org). The rat Cia3 locus was found to correspond to four human chromosomal segments, in chromosomes 2p12, 3p25.3, 7q34-36 and 10q11.23. The Cia2, Cia4 and Cia5 loci were found likely to correspond to single human chromosomal regions, 19q13.1, 22q12-13 and 17q21.33-25.2 respectively. The Oia2 locus was found to correspond to a segment in chromosome 12p13-12. We selected a few markers corresponding to the various loci at first. Later on markers were added for two regions for further delineation.

\section{Statistical analysis}

Since MS is considered a polygenic and possibly multifactorial disorder with an unknown mode of inheritance, nonparametric methods were used for linkage analysis. Linkage analysis was performed on data from multiplex families only. (a) The non-parametric linkage (NPL) analysis of the GENEHUNTER computer package. ${ }^{22}$ The NPL scores are

Table 1 Types of families and numbers of total individuals

\begin{tabular}{lll}
\hline Affected/family & Familes $(\mathrm{n})$ & Total individual $(\mathrm{n})$ \\
\hline 4 & 2 & 9 \\
3 & 8 & 47 \\
2 & 36 & 151 \\
1 & 28 & 79 \\
Total & 74 & 286 \\
\hline
\end{tabular}


Table 2 Location, characteristics and outcome of linkage analysis in MS of 27 microsatellite markers syntenic to rat autoimmune disease loci

\begin{tabular}{|c|c|c|c|c|c|c|}
\hline Rat loci & $\begin{array}{l}\text { Human homologous } \\
\text { loci }\end{array}$ & $\begin{array}{l}\text { Markers } \\
\text { used }\end{array}$ & $\begin{array}{l}\text { Distance to next } \\
\text { marker }(\mathrm{cM})\end{array}$ & $\begin{array}{l}\text { Genehunter } \\
\text { NPL-score }\end{array}$ & $\begin{array}{l}\text { APM } \\
\text { P-value }\end{array}$ & $\begin{array}{l}\text { ETDT } \\
\text { P-value }\end{array}$ \\
\hline \multirow[t]{11}{*}{ Cia3 } & $2 \mathrm{p} 12$ & CD8 & & -0.52 & 0.35 & 0.5 \\
\hline & $3 p 25$ & D3S1304 & 6.03 & 0.26 & 0.42 & 0.15 \\
\hline & $3 p 25.3$ & D3S2403 & & 0.69 & 0.03 & 0.32 \\
\hline & $7 q 34$ & D7S684 & 4.75 & -0.81 & 0.74 & 0.04 \\
\hline & $7 q 35$ & TCR $\beta / \mathrm{R}-\mathrm{M}$ & 0 & 0.49 & 0.0003 & 0.24 \\
\hline & $7 q 35$ & TCR $\beta /$ R-I & 0 & 0.62 & 0.06 & 0.22 \\
\hline & $7 q 35$ & $\mathrm{TCR} \beta / \mathrm{R}-\mathrm{G}$ & 0 & 0.76 & 0.03 & 0.14 \\
\hline & $7 q 35$ & TCRV $\beta 6.7$ & 2.53 & 1.16 & 0.06 & 0.07 \\
\hline & $7 q 36.1$ & D7S2511 & 2.61 & 0.53 & 0.29 & 0.008 \\
\hline & $7 q 36.1$ & D7S1826 & & -0.16 & 0.89 & 0.06 \\
\hline & $10 q 11.23$ & D10S1426 & & -0.3 & 0.42 & 0.64 \\
\hline \multirow[t]{10}{*}{ Oia2 } & $12 \mathrm{p} 13.3$ & D12S372 & 0.4 & 0.01 & 0.83 & 0.13 \\
\hline & $12 \mathrm{p} 13.3$ & D12S93 & 0.75 & 0.92 & 0.0002 & 0.014 \\
\hline & $12 \mathrm{p} 13.3$ & D12S356 & 0.37 & 0.61 & 0.016 & 0.29 \\
\hline & $12 \mathrm{p} 13.3$ & D12S374 & 0.41 & 1.16 & 0.05 & 0.09 \\
\hline & $12 \mathrm{p} 13.3$ & CD4 C/D & 0.06 & 0.12 & 0.89 & 0.39 \\
\hline & $12 \mathrm{p} 13.3$ & D12S1625 & 2.77 & 0.36 & 0.02 & 0.009 \\
\hline & $12 \mathrm{p} 13.3$ & D12S336 & 3.16 & -0.48 & 0.76 & 0.63 \\
\hline & $12 \mathrm{p} 13.3$ & D12S391 & 6.96 & 0.21 & 0.17 & 0.09 \\
\hline & $12 \mathrm{p} 12.3$ & D12S373 & 5.7 & 0.41 & 0.72 & 0.48 \\
\hline & $12 \mathrm{p} 12.1$ & D12S1042 & & 0.01 & 0.85 & 0.03 \\
\hline \multirow[t]{3}{*}{ Cia5 } & $17 q 21.33$ & D17S1301 & 27.35 & -0.79 & 0.86 & 0.36 \\
\hline & $17 q 25.2$ & D17S784 & 2.33 & -1.52 & 0.94 & 0.07 \\
\hline & $17 q 25.2$ & D17S1830 & & -0.16 & 0.56 & 0.028 \\
\hline Cia2 & $19 q 13.1$ & D19S246 & & -0.46 & 0.28 & 0.31 \\
\hline \multirow[t]{2}{*}{ Cia4 } & $22 q 12-13$ & PDGFB1 & 0 & -0.24 & 0.84 & 0.44 \\
\hline & $22 q 12-13$ & PDGFB2 & & 0.49 & 0.07 & 0.24 \\
\hline
\end{tabular}

model-independent and effectively measure the extent to which marker alleles shared by descent between affected individuals is greater than expected under random segregation. Initially, two-point linkage analysis was performed. In case the initial analysis was considered promising, arbitrarily defined as NPL $>1.0$ or APM $P$ value $<0.01$, additional markers were added between and flanking the original markers and multipoint linkage NPL analysis was performed.

(b) APM (affected pedigree member, version 2.10). ${ }^{23}$ Since this analysis is known to be sensitive to erroneous population marker allele frequencies, these were estimated from 148 normal controls.

(c) ETDT (extended transmission disequilibrium test, version $1.4),{ }^{24}$ which is a family-based linkage-disequilibrium test, was applied in transmission analysis of multiplex and singleton families together.

\section{Results}

Results are summarised in Table 2.

\section{A region syntenic to Cia2: 19q13.1}

The only selected marker in this locus failed to provide evidence for linkage (see Table 2). This fits well with our previously reported negative data concerning markers close to the neighbouring myelin-associated glycoprotein (MAG) gene. $^{25}$

Four regions syntenic to Cia3: 2p12, 3p25, 7q34-36 and $10 q 11.23$

For $2 \mathrm{q} 12$ and $10 \mathrm{q} 11.23$, we selected single marker, CD8 located intragenically in the CD8 gene and D10S1426 located in 10q11.23 to represent these two regions. As shown in Table 2 , there was no evidence for an importance of these two loci. One of two markers selected for 3p25, however, showed slight evidence for linkage $(P=0.03)$ by APM as well as a slightly positive NPL score of 0.69 . However, there was no indication of importance as observed by TDT.

In the initial screen, we selected four intragenic markers in the TCR $\beta$ region in 7q34-36 at first, partly due to the previous interest in this locus. Slightly positive linkage was observed both by NPL and APM analysis (see Table 2). Therefore, three additional markers were added. Altogether, five out of seven markers showed slightly positive NPL scores, with a maximum score of 1.16 (marker TCR $\beta$ 6.7). Multipoint analysis did not increase this score, as the maximum multipoint statistic by NPL was 0.77 . In order to avoid the negative sideeffects of multipoint analysis with flanking markers and allow all meioses on all pedigrees to be scored in the analysis, ${ }^{26}$ we also performed an analysis with only the five most tightly linked markers. However, this only increased the 
multipoint NPL score marginally to 0.94. Significant linkage was observed by APM ( $P=0.0003$ for marker TCR $\beta / \mathrm{R}-\mathrm{M})$ and TDT $(P=0.008$ for marker D7S511).

A region syntenic to Cia4: $22 \mathrm{q} 12-13$

For two selected markers in this region, no evidence for linkage was observed.

\section{A region syntenic to Cia5: $17 q 21-25$}

We investigated three markers in 17q21-25. Apart from a marginal transmission distortion for marker D17S1830, no evidence for linkage was observed.

\section{A region syntenic to Oia2: 12p13-12}

This locus includes the CD4 gene, a highly interesting candidate gene in MS. The observation of possible linkage in the neighbouring two markers (see Table 2) prompted us to add more flanking markers to obtain efficient delineation of the locus. Overall, the strongest evidence for linkage was observed for marker D12S374 by NPL analysis (1.16), and for marker D12S93 by APM $(P=0.00002)$. Here, three adjacent markers in a $1.1 \mathrm{cM}$ region scored positively by both NPL and APM analyses. As for the TCR $\beta$ locus, multipoint analysis did not increase the NPL score, which fell slightly to 1.01. On the other hand, a restricted analysis of only the most informative families (those containing affected sibling pairs) increased the NPL slightly to a maximum of 1.47 .

\section{Discussion}

We have observed possible evidence for linkage in MS for two loci, 7q34-35 and 12p13-12 in the comparatively homogeneous Swedish population. These loci were identified due to synteny with loci of clear importance for autoimmune model diseases in the rat, and also overlap with areas showing promising linkage in previous MS genomic screens (see Table 3). ${ }^{5,6}$ Furthermore, a similar approach has been shown to be successful concerning another strong candidate locus in MS, $5 \mathrm{p},{ }^{9}$ an area syntenic to a locus of importance for mouse EAE. ${ }^{10}$ In fact, also for this locus we have in the present material previously reported possible linkage as well as association. ${ }^{27}$

One of the identified loci, 7q34-36, contains the TCR $\beta$ gene cluster. The TCR $\beta$ gene has indeed been intensively investigated as a candidate susceptibility gene in MS. Thus, indications of linkage have been reported ${ }^{6,28,29}$ but also failed to be observed. $5,7,30$ Likewise, some studies have shown association $^{31,32}$ whereas others have not. ${ }^{33,34}$ These inconsistent findings have been obtained both by simple biallelic markers as well as by polyallelic microsatellite markers. In addition, in two frequently used mouse models of MS, EAE and Theiler's murine encephalomyelitis virus (TMEV) infection, the $\operatorname{TCR} \beta$ chain locus has been reported to be a major susceptibility gene if co-inherited with the major histocompatibility complex (MHC). ${ }^{13,35,36}$ In fact, several studies have indicated that the $\mathrm{Cia} 3$ region contains a gene that controls the development of several autoimmune disease-related traits. ${ }^{11,37,38}$

There are, naturally, a number of possible explanations for the discrepancy among studies on complex disorders such as MS. Locus heterogeneity may be present, where the absolute or relative importance of different loci vary between populations due to the interaction of genes or a different distribution of alleles. Further, the low relative risk of each genetic factor in polygenic disorders and a limited sample size easily lead to lack of adequate power for replication of previous observations. Finally, it may still be that some results are the effect of random variation and do not reflect the presence of a susceptibility locus. Anyhow, there are at present several promising observations concerning the TCR $\beta$ region in MS, hopefully inspiring further efforts.

The other most interesting locus in the present study was 12p13-12, being syntenic to the rat Oia2 locus. Previously, this region has been suggested to be of importance in the British genomic screen study. ${ }^{5}$ Intriguingly, the CD4 antigen has a prominent role in potentiating antigen recognition by helper $\mathrm{T}$ cells. Brown ${ }^{39}$ reported that CD4-deficient, T cell receptor transgenic $\mathrm{T}$ cells were incapable of $\mathrm{Th} 2$ differentiation after in vitro activation. Expression of a wild-type CD4 transgene corrected the Th2 defect of CD4-deficient mice in all immune responses tested. Interestingly, this region has substantial overlap also with loci of importance in myelinoligodendrocyte glycoprotein- (MOG)-induced EAE, ${ }^{13}$ experimental diabetes, ${ }^{40}$ lupus $^{41}$ and B. Pertussis-induced histamine sensitisation. ${ }^{42}$

As in a previous report, ${ }^{43}$ we arbitrarily used NPL $>1$ and APM $P<0.01$ to define a region as promising, well aware that this definition falls short of suggested criteria. ${ }^{44}$ Thus Landers and Kruglyak suggested a $P$ value of $<0.002$ to define a region 'suggestive'. Although we did observe such $P$ values for both main loci, most of our findings were less convincing. In addition, we have analysed our data for multiple markers with multiple methods and are aware that this may increase the risk of false positive results. We believe, however, that our conclusions are supported in three ways. First, the fact that several adjacent markers show similar results indicate that in the present material there is, in fact, a weak but true co-segregation of disease in these particular regions. Second, these exact regions were not only supported by previous findings in animal models but were also previously identified as interesting regions in MS as stated in Table 3. Third, in a key study, Becker et al pointed out the clustering of non-MHC loci in supposedly autoimmune polygenic disorders and several experimental model diseases. ${ }^{18}$ The present data add further support to this notion, as both 12p13-12 and 7q34-36 are among the loci pointed out by Becker. One interpretation of this pattern is, of course, that these loci harbour genes that are key regulators of pathogenic immune responses. Such genes would regulate autoimmune disease in a target organ-independent fashion and may be considered as 'autogenes'. ${ }^{45}$ 
Table 3 Summary of studied candidate chromosomal regions compared with previous human studies as well as studies in experimental autoimmune model diseases. Please note that, for human studies, suggestive evidence for linkage is indicated as positive, although falling short of, for instance, genome-wide significance

\begin{tabular}{|c|c|c|c|c|c|c|c|c|c|c|c|c|}
\hline \multirow[b]{2}{*}{ Human locus } & \multicolumn{3}{|c|}{ Present study } & \multicolumn{5}{|c|}{ Autoimmune models in rodents } & \multicolumn{4}{|c|}{ Published genomic screens } \\
\hline & $\begin{array}{l}N P L \\
>1.0\end{array}$ & $\begin{array}{l}T D T \\
\mathrm{P}<0.05\end{array}$ & $\begin{array}{l}A P M \\
\mathrm{P}<0.01\end{array}$ & $\begin{array}{l}\text { Rat locus } \\
\text { (chr) }\end{array}$ & $E A$ & $E A E$ & IDDM & ATD & US & UK & Canada & Finland \\
\hline $3 p 25$ & - & - & - & Cia3(4) & + & + & + & + & - & - & + & - \\
\hline $12 \mathrm{p} 13-12$ & + & + & + & Oia2(4) & + & + & & & - & + & - & - \\
\hline $17 q 22-25$ & - & - & - & Cia5(10) & + & + & & & - & + & - & - \\
\hline $19 q 13$ & - & - & - & $\mathrm{Cia} 2(1)$ & + & - & & & + & + & + & \pm \\
\hline
\end{tabular}

NPL, non-parametric linkage analysis; TDT, transmission disequilibrium test; APM, affected pedigree member analysis; EA, experimental arthritis; EAE, experimental allergic encephalomyelitis; IDDM, insulin dependent diabetes mellitus; ATD, autoimmune thyroid disease.

We are especially encouraged by the apparent significance in MS of genomic regions defined in experimental inflammatory diseases where prospects for positional cloning of genes are promising. After exact positioning in rats or mice, human susceptibility genes may be readily identified.

The initial response to the publication of the three genomic screens in MS in $1996^{5-7}$ was one of disappointment, ${ }^{46}$ since data supporting non-HLA loci seemed weak. However, subsequent data ${ }^{8,27,47}$ including the present study show a surprising consistence. Thus, based on available data, the following loci are likely to contain MS susceptibility genes having shown evidence for linkage: 6p21 (HLA complex), 5p, 17q21-25, 7pter-15, 7q34-36, 12p13-12, and $12 q 23$. It now seems reasonable to focus on identifying the responsible genes, particularly as this may be more rewarding than previously recognised due to the possible relevance in other autoimmune disorders.

\section{Acknowledgements}

This study was supported from the Swedish Medical Research Council (project numbers: 11023 and 11220), the European Commission (project number CT97-2422), the Society for the Neurologically Disabled, the Sigurd and Elsa Goljes Minne foundation, the Karolinska Institute, the Magn Bergvalls foundation, the Ake Wiberg foundation, the Bibbi and Nils Jensens Foundation and the Marcus Borgströms foundation.

\section{References}

1 Compston A: Genetic epidemiology of multiple sclerosis. J Neurol Neurosurg Psychiatry 1997; 62: 553-561.

2 Ebers GC, Sadovnick AD, Risch NJ: A genetic basis for familial aggregation in multiple sclerosis. Canadian Collaborative Study Group. Nature 1995; 377: 150-151.

3 Hillert J: Human leukocyte antigen studies in multiple sclerosis. Ann Neurol 1994; 36: S15-S17.

4 Oksenberg JR, Baranzini SE, Barcellos LF, Hauser SL: Multiple sclerosis: Genomic rewards. J Neuroimmunol 2001; 113: 171 184.

5 Sawcer S, Jones HB, Feakes R et al: A genome screen in multiple sclerosis reveals susceptibility loci on chromosome $6 \mathrm{p} 21$ and 17q22. Nat Genet 1996; 13: 464-468.
6 Haines JL, Ter-Minassian M, Bazyk A et al: A complete genomic screen for multiple sclerosis underscores a role for the major histocompatability complex. The Multiple Sclerosis Genetics Group. Nat Genet 1996; 13: 469-471.

7 Ebers GC, Kukay K, Bulman DE et al: A full genome search in multiple sclerosis. Nat Genet 1996; 13: $472-476$.

8 Kuokkanen S, Gschwend M, Rioux JD et al: Genomewide scan of multiple sclerosis in Finnish multiplex families. Am J Hum Genet 1997; 61: 1379 - 1387.

9 Kuokkanen S, Sundvall M, Terwilliger JD et al: A putative vulnerability locus to multiple sclerosis maps to $5 \mathrm{p} 14$-p12 in a region syntenic to the murine locus Eae2. Nat Genet 1996; 13: $477-480$

10 Sundvall M, Jirholt J, Yang HT et al: Identification of murine loci associated with susceptibility to chronic experimental autoimmune encephalomyelitis. Nat Genet 1995; 10: 313-317.

11 Jacob HJ, Pettersson A, Wilson D et al: Genetic dissection of autoimmune type I diabetes in the BB rat. Nat Genet 1992; 2 : $56-60$.

12 Pettersson A, Wilson D, Daniels T et al: Thyroiditis in the BB rat is associated with lymphopenia but occurs independently of diabetes. J Autoimmun 1995; 8: 493-505.

13 Dahlman I, Lorentzen JC, de Graaf KL et al: Quantitative trait loci disposing for both experimental arthritis and encephalomyelitis in the DA rat; impact on severity of myelin oligodendrocyte glycoprotein-induced experimental autoimmune encephalomyelitis and antibody isotype pattern. Eur J Immunol 1998; 28: 2188-2196.

14 Roth MP, Viratelle C, Dolbois L et al: A genome-wide search identifies two susceptibility loci for experimental autoimmune encephalomyelitis on rat chromosomes 4 and 10. I Immunol 1999; 162: $1917-1922$.

15 Dahlman I, Jacobsson L, Glaser A et al: Genome-wide linkage analysis of chronic relapsing experimental autoimmune encephalomyelitis in the rat identifies a major susceptibility locus on chromosome 9. J Immunol 1999; 162: 2581-2588.

16 Remmers EF, Longman RE, Du Y et al: A genome scan localizes five non-MHC loci controlling collagen-induced arthritis in rats. Nat Genet 1996; 14: 82-85.

17 Lorentzen JC, Glaser A, Jacobsson L et al: Identification of rat susceptibility loci for adjuvant-oil-induced arthritis. Proc Natl Acad Sci USA 1998; 95: 6383-6387.

18 Becker KG, Simon RM, Bailey-Wilson JE et al: Clustering of nonmajor histocompatibility complex susceptibility candidate loci in human autoimmune diseases. Proc Natl Acad Sci USA 1998; 95: $9979-9984$. 
19 Dahlman I, Wallstrom E, Weissert R et al: Linkage analysis of myelin oligodendrocyte glycoprotein-induced experimental autoimmune encephalomyelitis in the rat identifies a locus controlling demyelination on chromosome 18. Hum Mol Genet 1999; 8: $2183-2190$.

20 Poser CM, Paty DW, Scheinberg L et al: New diagnostic criteria for multiple sclerosis: guidelines for research protocols. Ann Neurol 1983; 13: 227 - 231.

21 Olerup O, Aldener A, Fogdell A: HLA-DQB1 and -DQA1 typing by PCR amplification with sequence-specific primers (PCR-SSP) in 2 hours. Tissue Antigens 1993; 41: 119-134.

22 Kruglyak L, Daly MJ, Reeve-Daly MP, Lander ES: Parametric and nonparametric linkage analysis: a unified multipoint approach. Am I Hum Genet 1996; 58: 1347 - 1363.

23 Weeks DE, Lange K: The affected-pedigree-member method of linkage analysis. Am J Hum Genet 1988; 42: 315-326.

24 Sham PC, Curtis D: An extended transmission/disequilibrium test (TDT) for multi-allele marker loci. Ann Hum Genet 1995; 59 $323-336$.

$25 \mathrm{He}$ B, Xu C, Yang B et al: Linkage and association analysis of genes encoding cytokines and myelin proteins in multiple sclerosis. J Neuroimmunol 1998; 86: 13 - 19 .

26 Pajukanta P, Nuotio I, Terwilliger JD et al: Linkage of familial combined hyperlipidaemia to chromosome 1q21-q23. Nat Genet 1998; 18: 369-373.

$27 \mathrm{Xu} \mathrm{C}$, Dai Y, Fredrikson S, Hillert J: Association and linkage analysis of candidate chromosomal regions in multiple sclerosis: indication of disease genes in 12q23 and 7ptr-15. Eur J Hum Genet 1999; 7: 110-116.

28 Seboun E, Robinson MA, Doolittle TH et al: A susceptibility locus for multiple sclerosis is linked to the T cell receptor beta chain complex. Cell 1989; 57: $1095-1100$.

29 Wood NW, Sawcer SJ, Kellar-Wood HF et al: The T-cell receptor beta locus and susceptibility to multiple sclerosis. Neurology, 1995; 45: $1859-1863$.

30 Lynch SG, Rose JW, Petajan JH et al: Discordance of T-cell receptor beta-chain genes in familial multiple sclerosis. Ann Neurol 1991; 30: 402-410.

31 Epplen C, Jackel S, Santos EJ et al: Genetic predisposition to multiple sclerosis as revealed by immunoprinting. Ann Neurol 1997; 41: $341-352$.

32 Hockertz MK, Paty DW, Beall SS: Susceptibility to relapsingprogressive multiple sclerosis is associated with inheritance of genes linked to the variable region of the TcR beta locus: use of affected family-based controls. Am J Hum Genet 1998; 62: 373 385

33 Hillert J, Leng C, Olerup O: No association with germline T cell receptor beta-chain gene alleles or haplotypes in Swedish patients with multiple sclerosis. J Neuroimmunol 1991; 32: $141-147$.
34 Wei S, Charmley P, Birchfield RI, Concannon P: Human T-cell receptor $\mathrm{V}$ beta gene polymorphism and multiple sclerosis. Am J Hum Genet 1995; 56: 963 -969.

35 Melvold RW, Jokinen DM, Knobler RL, Lipton HL: Variations in genetic control of susceptibility to Theiler's murine encephalomyelitis virus (TMEV)-induced demyelinating disease. I. Differences between susceptible $\mathrm{SJL} / \mathrm{J}$ and resistant $\mathrm{BALB} / \mathrm{c}$ strains map near the T cell beta-chain constant gene on chromosome 6 . J Immunol 1987; 138: 1429-1433.

36 Rodriguez M, Patick AK, Pease LR, David CS: Role of T cell receptor $\mathrm{V}$ beta genes in Theiler's virus-induced demyelination of mice. J Immunol 1992; 148: 921 - 927.

37 Baker D, Rosenwasser OA, O'Neill JK, Turk JL: Genetic analysis of experimental allergic encephalomyelitis in mice. I Immunol 1995; 155: 4046-4051.

38 Griffiths MM, Encinas JA, Remmers EF, Kuchroo VK, Wilder RL: Mapping autoimmunity genes. Curr Opin Immunol 1999; 11: $689-700$.

39 Brown DR, Moskowitz NH, Killeen N, Reiner SL: A role for CD4 in peripheral T cell differentiation. J Exp Med 1997; 186: 101 107.

40 Ghosh S, Palmer SM, Rodrigues NR et al: Polygenic control of autoimmune diabetes in nonobese diabetic mice. Nat Genet 1993; 4: 404-409.

41 Kono DH, Burlingame RW, Owens DG et al: Lupus susceptibility loci in New Zealand mice. Proc Natl Acad Sci USA 1994; 91 : $10168-10172$.

42 Sudweeks JD, Todd JA, Blankenhorn EP et al: Locus controlling Bordetella pertussis-induced histamine sensitization (Bphs), an autoimmune disease-susceptibility gene, maps distal to T- cell receptor beta-chain gene on mouse chromosome 6. Proc Natl Acad Sci USA 1993; 90: 3700-3704.

43 D'Alfonso S, Nistico L, Zavattari P et al: Linkage analysis of multiple sclerosis with candidate region markers in Sardinian and Continental Italian families. Eur J Hum Genet 1999; 7: 377 385.

44 Lander ES, Kruglyak L: Genetic dissection of complex traits: guidelines for interpreting and reporting linkage results. Nat Genet 1995; 11: $241-247$

45 Mountz JD, Talal N: Retroviruses, apoptosis and autogenes. Immunol Today 1993; 14: 532-536.

46 Bell JI, Lathrop GM: Multiple loci for multiple sclerosis. Nat Genet 1996; 13: 377-378

47 Oturai A, Larsen F, Ryder LP et al: Linkage and association analysis of susceptibility regions on chromosomes 5 and 6 in 106 Scandinavian sibling pair families with multiple sclerosis. Ann Neurol 1999; 46: 612-616. 